\title{
Primeiro relato do parasitóide Pachycrepoideus vindemiae Rondani (Hymenoptera: Pteromalidae) parasitando pupas Sarcodexia lambens Wiedemann (Diptera: Sarcophagidae) no Brasil
}

\author{
First report on Pachycrepoideus vindemiae Rondani (Hymenoptera: Pteromalidae) \\ parasitizing pupae of Sarcodexia lambens Wiedemann \\ (Diptera: Sarcophagidae) in Brazil.
}

Carlos Henrique Marchiori ${ }^{1}$ Luiz Alex Pereira $^{1}$ Otacilio Moreira Silva Filho $^{2}$

\section{-NOTA-}

RESUMO

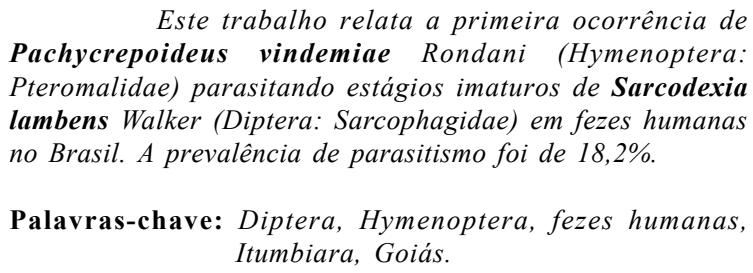
Pachycrepoideus vindemiae Rondani (Hymenoptera: Pteromalidae) parasitando estágios imaturos de Sarcodexia lambens Walker (Diptera: Sarcophagidae) em fezes humanas no Brasil. A prevalência de parasitismo foi de 18,2\%.

Palavras-chave: Diptera, Hymenoptera, fezes humanas, Itumbiara, Goiás.

\section{ABSTRACT}

This work reports, for the first time, the occurrence of Pachycrepoideus vindemiae Rondani (Hymenoptera: Pteromalidae) parasitizing immature stages of Sarcodexia lambens Walker (Diptera: Sarcophagidae) in human feces in Brazil. The parasitism prevalence was $18.2 \%$.

Key words: Diptera, Hymenoptera, human feces, Itumbiara, Goiás.

Os dípteros muscóides das famílias Calliphoridae, Fanniidae, Muscidae e Sarcophagidae são potenciais vetores de agentes etiológicos, como: vírus, bactérias, cistos de protozoários e ovos de helmintos (GREENBERG, 1971).

Os Sarcophagidae são insetos vivíparos, raramente ovovivíparos. São reconhecidas 600 espécies de Sarcophagidae na região Neotropical (SHEWELL, 1987). Sarcodexia lambens Wiedemann (1861)) esta amplamente distribuída nas Américas, sendo encontrada do Sul dos Estados Unidos da América até a Argentina (LOPES \& LEITE 1989). Essa espécie coloniza em matéria orgânica animal como fezes humanas, fezes de gado bovino e fígado bovino usadas como iscas (ROCHA \& MENDES, 1996; MARCHIORI et al., 2000a).

A família Pteromalidae (Hymenoptera, Chalcidoidea) inclui um grande número de espécies parasitóides, muitas das quais têm importância no controle biológico de muscóides sinantrópicos (CARDOSO \& MILWARD-DE-AZEVEDO, 1996). Eles podem ser solitários ou gregários, ectoparasitóides ou

${ }^{1}$ Professor Doutor do Departamento de Ciências Naturais do Instituto Luterano de Ensino Superior de Itumbiara - GO, ILESULBRA, Avenida Beira Rio, 1001, Bairro Nova Aurora, Itumbiara - Goiás, 75.500-000, Fax (62) 431-8239. E-mail: pesquisa.itb@ ulbra.br. Autor para correspondência.

${ }^{2}$ Aluno do curso de graduação em Ciências Biológicas. 
endoparasitóides, parasitóides primários ou secundários, coinobiontes ou idiobiontes. A maioria é idiobionte e muitos desenvolvem-se como ectoparasitóides em larvas ou pupários de Diptera, Coleoptera, Hymenoptera, Lepidoptera e Siphonaptera (IORIATTI, 1995).

Pachycrepoideus vindemiae é considerado um parasitóide solitário de numerosos Diptera nas famílias Anthomyiidae, Calliphoridae, Muscidae, Sarcophagidae, Tachinidae, Tephritidae e outras. Esta espécie apresenta ampla distribuição geográfica sendo também encontrada na América do Norte, Canadá, África (HANSON \& GUALD, 1995). O objetivo deste trabalho é relatar a primeira ocorrência do parasitóide Pachycrepoideus vindemiae parasitando Sarcodexia lambens no Brasil.

O estudo foi realizado na mata da fazenda da Faculdade de Agronomia localizada no município de Itumbiara, $\mathrm{GO}\left(18^{\circ} 25^{\prime} \mathrm{S}-49^{\circ} 13^{\prime} \mathrm{W}\right)$. Esta mata possui 1,5 hectares de floresta constituída por mata ciliar, que acompanha o rio Paranaíba, gradando para mata mesófila semidecídua e cerradão. Ela apresenta histórico de corte seletivos de árvores, queimadas e encontra-se rodeada por culturas de cana-de-açúcar e pastagens. O clima da região é do tipo AW, segundo a classificação de Köppen (ROSA et al., 1991) com invernos secos e verões chuvosos. É um tipo de clima de savana, onde a precipitação anual é maior que dez vezes a precipitação do mês mais seco, sendo menor que $60 \mathrm{~mm}$. A concentração das chuvas ocorre durante os meses mais quentes, intercalando-se um período de 4 a 5 meses secos, quando o déficit hídrico é acentuado (NISHIYAMA, 1989).

Procedeu-se a atração de moscas por meio de armadilhas construídas com lata de coloração preta fosca, medindo cerca de $19 \mathrm{~cm}$ de altura por $9 \mathrm{~cm}$ de diâmetro, com duas aberturas tipo venezianas, localizadas no terço inferior para permitirem a entrada dos insetos. Na parte superior das latas, foram acoplados funis de nylon, abertos nas extremidades, com bases voltadas para baixo e envolvidos em sacos plásticos, cuja remoção permitiria a coleta das moscas e parasitóides. Serviram como isca fezes humanas depositadas no interior das latas, sobre uma camada de terra. Utilizaram-se 5 armadilhas que foram penduradas em árvores a 1 metro do solo e a 2 metros uma das outras em uma mata.

Os indivíduos coletados foram levados para o laboratório, sacrificados com éter etílico e conservados em álcool $70 \%$ para posterior identificação. O conteúdo das armadilhas foi colocado em recipientes plásticos contendo uma camada de areia para servir de substrato à pupação das larvas. Peneirada esta areia (após 15 dias de sua colocação no campo), dela se extraíram as pupas, que em seguida foram colocadas individualmente, em cápsulas de gelatina (número 00) para obtenção de moscas e/ou parasitóides. A prevalência de parasitismo foi calculada através do número de pupas parasitadas/número total de pupas coletadasx 100 .

No período de maio a setembro de 2001 , em fezes humanas coletaram-se 22 pupas de Sarcodexia lambens, das quais emergiram parasitóides da espécie Pachycrepoideus vindemiae, em quatro com uma prevalência de parasitismo de 18,2\%. Foram constatados em Iguapé, MG, $1,1 \%$ e 3,7\% de parasitismo de $\boldsymbol{P}$. vindemiae em pupas de Musca domestica L. (Diptera: Muscidae) e Chrysomya putoria Wiedemann (Diptera: Calliphoridae), respectivamente (SERENO \& NEVES, 1993). Em Itumbiara, P. vindemiae foi encontrado parasitando Fannia pusio Wiedemann (Diptera: Fanniidae) M. domestica, Sarcophagula occidua Fabricius (Dfiptera: Sarcophagidae) com 0,1\%, 0,4\% e $0,2 \%$ de parasitismo, respectivamente (MARCHIORI et al., 2000a; MARCHIORI et al., 2000b).

Provavelmente, a alta prevalência de parasitismo encontrada neste estudo se deve à amostragem mais extensiva que a realizada por MARCHIORI et al. (2000a; 2000b).

No Brasil, este trabalho representa o primeiro relato do parasitóide $\boldsymbol{P}$. vindemiae utilizando como hospedeiro S. lambens.

\section{REFERÊNCIAS BIBLIOGRÁFICA}

CARDOSO, D.; MILWARD-DE-AZEVEDO, E. Aspectos da biologia de Nasonia vitripennis (Walker), (Hymenoptera, Pteromalidae) em pupas de Chrysomya megacephaga (Fabricius) e C. albicepas (Wiedemann) (Diptera, Calliphoridae), sob condições de laboratório. Revista Brasileira de Entomologia, v.40, p.143-146, 1996.

IORIATTI, M.C.S.S. Contribuição ao estudo da biologia e taxonomia dos Hymenoptera parasitóides de Diptera das famílias Tephritidae e Lonchaeidae. 1995. 92f. Dissertação (Mestrado em Ecologia e Biologia Evolutiva) -Curso de Pós-graduação em Ciências Biológicas, Universidade Federal de São Carlos.

GREENBERG, B. Flies and diseases. Ecology, classification and biotic associations. Princeton : Princeton University, 1971. $856 \mathrm{p}$.

HANSON, P.E.; GAULD, I.D. The Hymenoptera of Costa Rica. Oxford : University, 1995. 893p.

LOPES, H.S.; LEITE, A.C.R. Morphology of the egg of Sarcodexia lambens (Diptera: Sarcophagidae). Memórias Instituto Oswaldo Cruz, Rio de Janeiro, v.84, n.4, p.497500, 1989 . 
MARCHIORI, C.H. et al. Dípteros muscóides de importância médica e veterinária e seus parasitóides em Goiás. Arquivos Brasileiro Medicina Veterinária e Zootecnia, v.52, n.4, p. 350-353, 2000a.

MARCHIORI, C.H. et al. Dípteros muscóides associados com fezes bovinas e seus parasitóides em Goiás. Arquivos Brasileiro Medicina Veterinária e Zootecnia, v.52, n.4, p.354$356,2000 b$

NISHIYAMA, L. Geologia do município de Uberlândia e áreas adjacentes. Sociedade \& natureza, v.1, p.9-16, 1989.

ROCHA, U.R.; MENDES, J. Pupation of Dermatobia hominis (L. Jr., 1781) (Diptera: Cuterebridae) associated with Sarcodexia lambens (Wiedemann, 1830) (Diptera: Sarcophagidae). Me- mórias Instituto Oswaldo Cruz, Rio de Janeiro, v.91, n.3, p.299-300, 1996.

ROSA, R.; LIMA, S.C.; ASSUNÇÃO, W.L. Abordagem preliminar das condições climáticas de Uberlândia (MG). Sociedade \& natureza, v.3, p.91-108, 1991.

SERENO, F.T.P.S.; NEVES, D. Microhimenópteros (Pteromalidae) parasitóides de Diptera (Muscidae, Otitidae) em uma granja de bovinos em Igarapé, Estado de Minas Gerais, Brasil. Revista Brasileira de Entomologia, v.37, p.563567, 1993.

SHEWELL, G.E. Manual of Neartic Diptera. In : Sarcophagidae. Canada : Research Branch Agriculture Canada, 1987. p.1159-1186. 